\title{
Analisis Sikap Spiritual, Sosial Dan Budaya Lokal Dalam Kurikulum 2013 Tema Sejarah Peradaban Indonesia Kelas V Sekolah Dasar
}

\author{
Laili Alfi Rahmatin, A.A.I.N. Marhaeni, I. M. Gunamantha \\ Program Studi Pendidikan Dasar, Program Pascasarjana \\ Universitas Pendidikan Ganesha \\ Singaraja, Indonesia \\ e-mail: alfi.rahmatin@pasca.undiksha.ac.id; ngurah.marhaeni@pasca.undiksha.ac.id; \\ md_gunamantha@yahoo.com
}

\begin{abstract}
Abstrak.Penelitian ini bertujuan untuk menganalisis dan mendeskripsikan nilai-nilai sikap dan nilai-nilai budaya lokal pendukungnya dalam kurikulum 2013 tema Sejarah Peradaban Indonesia di kelas $\mathrm{V}$ sekolah dasar. Subjek penelitian ini adalah buku guru dan buku siswa tema Bangga Sebagai Bangsa Indonesia kelas V, guru kelas V, orang tua siswa, guru SBdP dan budayawan. Data dikumpulkan menggunakan pedoman pencatatan dokumen dan wawancara. Data dianalisis secara deskriftif kualitatif. Hasil penelitian ini menunjukkan bahwa ditemukan; 1) nilainilai sikap spiritual yang termuat ketaatan beribadah dan berprilaku syukur., 2) nilai-nilai sikap sosial yang termuat yaitu jujur, disiplin, tanggung jawab, dan percaya diri, dan 3) nilai-nilai budaya lokal yang muncul dalam aktivitas anak kelas tinggi yang mendukung pengembangan nilai-nilai sikap pada tema Sejarah Peradaban Indonesia yaitu, beberapa jenis permainan tradisional, cerita anak (satua), bernyanyi (magending), mengucapkan salam, dan kegiatan sembahyang (mebanten). Selanjutnya dari hasil temuan-temuan tersebut juga dihasilkan prototipe buku cerita anak berbasis budaya lokal pada tema Sejarah Peradaban Indonesia di kelas V sekolah dasar.
\end{abstract}

\section{Kata kunci: Budaya Lokal, Buku Cerita, Sikap}

Abstract. This study aimed to analyze and describe the attitude value and the local cultural value of its elements in Curriculum 2013 with the theme of Indonesian Civilizations History for 5th grade of elementary school. The subject of this study are teacher's book and student's book entitle Bangga Sebagai Banga Indonesia for 5th grade, 5th grade teacher, student's parents, Art and Culture teacher, and humanist. The instrument used to collect the data were document recording and interview. This study used descriptive qualitative method to analysis the data. The results show that; (1) the spiritual attitude which appear is the obedience to worship and grateful behavior, (2) Social attitude that show up is honesty, discipline, responsibility, and confidence, (3) Local Culture value that can be seen from the activity of higher grade students that support the development of attitude value with the theme of Indonesian Civilizations History are traditional game, children story/tales (satua), singing (megending), greeting, worshiping activity (mebanten). Those results generated the Prototype of children story book based on local culture with the theme of Indonesian Civilizations History for 5th grade of elementary school.

Keywords: Local Culture, Story Book, Attitude

\section{PENDAHULUAN}

Kurikulum 2013 adalah kurikulum berbasis kompetensi yang dirumuskan secara terpadu yang dimana kompetensi sikap, pengetahuan dan keterampilan harus dikuasai oleh siswa. Didalamnya juga dirumuskan pembelajaran dan penilaian untuk memastikan ketercapaian kompetensi yang diinginkan. Kompetensi tersebut disampaikan dalam kompetensi inti yaitu Kompetensi inti I tentang sikap spiritual, Kompetensi Inti II tentang sikap sosial, Kompetensi III tentang pengetahuan, dan Kompetensi IV tentang keterampilan.

Salah satu perbedaan antara kurikulum 2013 dengan kurikulum sebelumnya adalah 
memiliki pedoman pegangan buku guru dan buku siswa yang disediakan secara langsung oleh pemerintah sebagai buku wajib ketika proses pembelajaran berlangsung. Pendekatan yang digunakan yakni pendekatan saintifik. Dimana pembelajaran saintifik merupakan pembelajaran yang berpusat pada siswa sehingga siswa dituntut untuk menemukan sendiri materi yang berkaitan dengan mata pelajaran tertentu (Fathurrahman, 2015:115).

Langkah yang harus diambil oleh setiap guru adalah mengintegrasikan sikap spiritual dan sikap sosial dalam pembelajaran, baik dalam perencanaan dan pelaksanaan pembelajaran. Pada penelitian yang dilakukan oleh Ariantini, dkk (2014) berpendapat bahwa impelementasi pengintegrasian sikap spiritual dan sikap sosial dalam perencanaan terletak pada komponen tujuan, langkah-langkah, dan penilaian pembelajaran. Pelaksanaannya dilakukan dengan cara memberikan motivasi atau dorongan, peringatan, arahan, teguran, penugasan, dan penguatan kepada siswa saat mengikuti kegiatan pembelajaran. Hambatannya terletak pada perencanaan dan pelaksaannya.

Buku-buku yang dikeluarkan oleh pemerintah, sudah berapa kali mengalami revisi, hal ini dilakukan dengan tujuan untuk pengembangan kurikulum dan mengimplementasikannya dalam kegiatan pembelajaran. Sejak diberlakukannya Kurikulum 2013, masih ditemukan adanya ketidaksesuaian isi buku dengan SKL, KI dan $\mathrm{KD}$, kemudian kedalaman materi yang tertuang dalam Buku Siswa masih perlu ditinjau dari karakteristik peserta didik. Karena jika ada yang dianggap kurang sesuai dengan karakteristik peserta didik di sekolah, hendaknya guru menindak lanjuti dengan memberikan tambahan-tambahan penjelasan seperlunya. Selain itu, dalam penerapan pendekatan yang digunakan, apakah sudah memfasilitasi peserta didik untuk melakukan kegiatan-kegiatan seperti yang diharapkan dalam pendekatan saintifik (dalam Sutrisno, 2016).

Materi yang masih bersifat ekspositori belum sesuai, ditambah dengan Kemendikbud melalui Peraturan Pemerintah nomor 23 tahun
2015 tentang penumbuhan budi pekerti meluncurkan sebuah gerakan GLS (Gerakan Literasi Sekolah) yang bertujuan untuk menumbuhkan sikap budi pekerti luhur kepada anak-anak melalui bahasa. Anak-anak pada usia Sekolah Dasar merupakan usia emas sehingga penting untuk menanamkan nilai-nilai budi pekerti luhur mereka. Sejalan hal tersebut (Setiawan: 2016) mengemukakan Gerakan literasi sekolah mempunyai tujuan untuk menumbuhkembangkan budi pekerti peserta didik melalui pembudayaan ekosistem literasi sekolah agar mereka menjadi pembelajar sepanjang hayat. Dimana. Sederhananya setiap anak diwajibkan membaca buku-buku bacaan cerita lokal dan cerita rakyat yang memiliki kearifan lokal dalam materi bacaannya sebelum pelajaran kelas dimulai.

Permasalahan lain yang ditemukan adalah konten uraian pembelajaran dalam buku kurang efisien dalam memuat nilai-nilai sikap dan muatan pembelajaran. Ditemukan beberapa konten pembelajaran yang kurang mampu mengoptimalkan penanaman nilainilai sikap kepada peserta didik. Selain itu, beberapa buku kurang mampu mengangkat muatan-muatan pembelajaran yang ada secara maksimal. Sehingga, sangat membatasi peserta didik untuk memeroleh ilmu pengetahuan apabila hanya mengandalkan buku tersebut.

Salah satu upaya alternatif yang dirasa efektif digunakan untuk mengembangkan nilai-nilai sikap adalah dengan memanfaatkan peran budaya lokal. Budaya lokal merupakan sarana yang efektif dalam menanamkan nilainilai dan pengetahuan ke dalam diri peserta didik. Kebudayaan lokal yang terdiri dari kepercayaan-kepercayaan, nilai-nilai, pengetahuan-pengetahuan, hubungan yang terstruktur, sistem simbol bahasa lisan dan tulis sangat penting dalam pembelajaran sikap.

Konsep budaya lokal Bali dalam kehidupan anak sekolah dasar menurut Made Taro dalam Guna (2014:47) adalah budaya lokal yang akrab dengan kehidupan anak yang menyertai aktivitas anak dalam bermain, bernyanyi, mendengarkan cerita (satua), 
bernyanyi (gending rare), mengucapkan salam, dan kewajiban sembahyang (mebanten). Bermain dalam budaya lokal yaitu bermain permainan tradisional Bali, bernyanyi dalam budaya lokal yaitu bernyanyi lagu anak-anak (gending rare), mendengarkan cerita dalam budaya lokal disebut ningehangsatua, mengucapkan salam yang dimaksud adalah salam budaya lokal, dan kewajiban bersembahyang dalam budaya lokal disebut mebanten.

Hal-hal di atas menjadi landasan pemikiran bahwa, nilai-nilai budaya lokal yang diturunkan ke dalam beberapa jenis aktivitas, akan sangat baik untuk mengembangkan nilai-nilai sikap. Maka, aktivitas budaya lokal tersebut dapat dijadikan sebagai suplemen dalam menunjang pembelajaran kurikulum 2013 khususnya untuk anak kelas tinggi. Namun, nilai-nilai budaya lokal yang mampu memuat nilai-nilai sikap sesuai dengan K-13 belum teridentifikasi. Telah ada penelitian sejenis yang dilakukan oleh Sukesari (2013), yang berhasil menganalisis dan memaparkan beberapa aktivitas budaya lokal bali yang memiliki keterkaitan dengan nilai sikap spiritual dan sosial dalam kurikulum 2013 pada anak kelas rendah. Namun penelitian yang ditujukan untuk kelas tinggi masih belum teridentifikasi. Maka dari itu perlu dilakukan analisis mengenai nilai-nilai sikap di kelas tinggi, khususnya di Kelas V pada tema Sejarah Peradaban Indonesia serta kajian nilai-nilai budaya lokal pendukungnya. Lebih lanjut hasil analisis ini dapat diarahkan pada penyusunan prototipe buku cerita anak yang nantinya dapat dikembangkan menjadi sebuah buku cerita anak, yang bisa difungsikan sebagai suplemen buku pelajaran yang dapat mengembangkan nilai sikap anak sesuai dengan pembelajaran tema Sejarah Peradaban Indonesia Kelas V sekolah dasar Kurikulum 2013.

\section{METODE PENELITIAN}

Jenis Penelitian yang dilaksanakan merupakan penelitian deskriptif kualitatif. Penelitian Deskriptif adalah suatu penelitian yang berusaha mendeskripsikan suatu fenomena atau peristiwa secara sistematis dan apa adanya. Subjek penelitian adalah pihakpihak yang dijadikan sebagai sampel dalam sebuah penelitian.Subjek penelitianberupa benda yakni buku guru dan buku siswa pembelajaran tematik tema Sejarah Peradaban Indonesia kelas V kurikulum 2013. Subjek penelitian dari informan adalah: Budayawan (3 orang), Guru kelas V (3 orang), Guru Seni Budaya dan Prakarya (SBdP) (3 orang), dan Orang tua siswa kelas V (3 orang).

Variabel-variabel dalam penelitian ini adalah: (1) Nilai - nilai sikap spiritual, (2) sikap sosial, (3) ruang lingkup materi muatan pembelajaran IPA dan (3) budaya lokal dalam kehidupan anak kelas tinggi sekolah dasar. Metode pencatatan dokumen dan wawancara digunakan untuk mengumpulkan data tentang muatan nilai-nilai sikap dan muatan pembelajaran IPA pada kurikulum 2013. Dokumen yang digunakan meliputi buku guru, buku siswa tema Sejarah Peradaban Indonesia kelas V Sekolah Dasar. Metode wawancara digunakan dengan tujuan menggali informasi dari narasumber (budayawan, guru kelas V, guru SBdP, dan orang tua siswa kelas $\mathrm{V}$ sekolah dasar) tentang nilai - nilai budaya lokal berupa aktivitas anak kelas awal yang mendukung nilai spiritual dan sosial pada pembelajaran tematik terpadu dengan tema Sejarah Peradaban Indonesia kelas V Sekolah Dasar

Analisis data yang dilakukan dalam penelitian ini yaitu metode analisis deskriptif kualitatif digunakan untuk menjustifikasi pencatatan dokumen mengenai nilai-nilai sikap dan muatan pembelajaran IPA yang terdapat pada buku guru dan buku siswa pada tema Sejarah Peradaban Indonesia di kelas V Sekolah Dasar. Mengklasifikasi hasil wawancara dengan narasumber budayawan, guru kelas, guru SBdP, dan orang tua siswa untuk dapat mengetahui dimensi nilai budaya lokal yang sesuai dengan nilai sikap spiritual dan sosial pada tema Sejarah Peradaban Indonesia kelas V Sekolah Dasar.

\section{HASIL DAN PEMBAHASAN}

Penelitian ini menghasilkan data-data melalui pencatatan/studi dokumen yang termuat pada buku guru dan buku siswa 
tentang nilai-nilai sikap dan muatan pembelajaran yang terkandung dalam buku kelas V Sekolah Dasar tema Sejarah Peradaban Indonesia, dan data untuk budaya lokal Bali yang dikumpulkan melalui wawancara dengan berbagai narasumber antara lain, budayawan, guru SBdP, guru kelas, dan orang tua siswa. Hasil pengumpulan data tersebut setelah ditabulasi selanjutnya dianalisis, sehingga data-data yang diperoleh melalui pencatatan dokumen dan wawancara dapat menjadi dasar perancangan prototype teoritik buku cerita anak berbasis budaya lokal Bali. Adapun hasil-hasil penelitian yang diperoleh berdasarkan hasil analisis dan wawancara adalah sebagai berikut.

Sikap spiritual terdiri atas beberapa aspek sikap, diantaranya 1) ketaatan beribadah, 2) berperilaku syukur, 3) berdoa sebelum dan sesudah berkegiatan, dan 4) toleransi dalam beribadah. Berdasarkan hasil analisis, ditemukan dua aspek yang muncul pada tema Sejarah Peradaban Indonesia yakni ketaatan beribadah dan berperilaku syukur. Aspek berperilaku syukur memiliki frekuensi kemunculan lebih banyak secara signifikan dibandingkan dengan aspek lain. Hal tersebut menunjukkan bahwa berperilaku syukur mendapat penekanan pada tema Sejarah Peradaban Indonesia di kelas V sekolah dasar.

Nilai sikap sosial terdiri atas beberapa aspek sikap diantaranya; 1) jujur, 2) disiplin, 3) tanggung jawab, 4) santun, 5) peduli, dan 6) percaya diri. Analisis yang dilakukan terhadap buku guru dan buku siswa kelas V tema Sejarah Peradaban Indonesia menghasilkan beberapa temuan muatan nilainilai sikap sosial. Berdasarkan hasil analisis, ditemukan empat dari enam aspek sikap sosial muncul pada tema Sejarah Peradaban Indonesia yakni jujur, disiplin, tanggung jawab, dan percaya diri. Berdasarkan kemunculan, aspek jujur lebih mendominasi daripada yang lainnya. Hal ini menunjukkan bahwa aspek sikap jujur mendapatkan penekanan pada tema Sejarah Peradaban Indonesia. Namun, untuk aspek sikap sosial lainnya yakni disiplin, tanggung jawab, dan percaya diri tetap diperhitungkan.

Selain muatan nilai sikap dan muatan pembelajaran, hasil lain dari penelitian ini adalah muatan budaya lokal untuk anak SD kelas tinggi. Terdapat 5 aktivitas anak kelas tinggi yang ditetapkan sebagai acuan untuk menggali informasi tentang konten-konten budaya lokal bali yang dapat dikembangkan ke dalam bentuk buku cerita anak. Kelima aktivitas tersebut adalah permainan tradisional bali, cerita tradisional bali (satua), nyanyian tradisional (gending), pengucapan salam tradisional bali, dan kewajiban sembahyang (mebanten).

Berdasarkan wawancara yang dilkakukan, diperoleh jenis permainan tradisional bali untuk anak kelas tinggi antara lain Makering-keringan (kering keb), Megalagalaan, Mecingklak, Main Tali, Tembing (dengkleng), meong-meongan, tajog, gangsing, dan magoak-goakan

Untuk jenis cerita anak (satua) untuk anak kelas tinggi berdasarkan hasil wawancara antara lain Maya denawa, mengkuwuk, Kunang-kunang ngaba api, cupak gerantang, I belog, men tiwas lan men sugih, I bawang teken I kesuna, Tuwung Kuning, Pan Balang Tamak, I Siap Selem, I Kekua. lutung teken kambing, Pedanda Baka, dan Kebo iwa.

Sementara untuk nyanyian (gending) untuk anak SD kelas tinggi yang diperoleh berdasarkan hasil wawancara antara lain ketut garing, bebek putih jambul, meong-meong, guak maling taluh, made cenik, sumping waluh, ratu anom, pupuh pucung, pupuh mijil. juru pencar, jenggot uban, pupuh maskumambang, dan pupuh ginada.

Untuk aspek budaya lokal lainnya yakni salam yang biasa diucapkan anak SD kelas tinggi berdasarkan hasil wawancara antara lain Om Swastiastu, Rahajeng semeng, Selamat Pagi, dan selamat siang.

Kebiasaan sembahyang (mebanten) untuk anak SD kelas tinggi yang diperoleh berdasarkan hasil wawancara antara lain mebanten ajengan/banten ketipat. canang, mebanten saiban, mebanten wedang, masegeh dan mebanten rahinan (purnama, tilem, 
saraswati, dll) Berdasarkan studi dokumen terhadap buku guru dan buku siswa dalam pembelajaran tematik tema Sejarah Peradaban Indonesia kurikulum 2013 di kelas $\mathrm{V}$, ditemukan nilai sikap sosial yang termuat yaitu jujur, disiplin, tanggung jawab, dan percaya diri. Sikap sosial yang termuat dalam Kurikulum 2013 di kelas V mengacu pada Permendikbud No. 21 tahun 2016 ditunjukkan melalui perilaku jujur, disiplin, tanggung jawab, santun, peduli, dan percaya diri dalam berinteraksi dengan keluarga, teman, guru, dan tetangganya serta cinta tanah air Tentunya hal ini menunjukkan bahwa buku guru dan buku siswa telah memuat sikap sosial sebagai mana yang diharapkan secara yuridis.

Hasil studi dokumen yang dilakukan terhadap buku guru dan buku siswa kelas V tema Sejarah Peradaban Indonesia menunjukkan bahwa indikator sikap sosial yang termuat secara tersurat dalam buku melalui uraian kegiatan pembelajarannya antara lain jujur, disiplin, tanggung jawab, dan percaya diri. Kemunculan aspek-aspek sikap tersebut telah menunjukkan bahwa buku pelajaran kurikulum 2013 kelas V tema Sejarah Peradaban Indonesia telah memuat nilai sikap sosial secara tersurat di dalamnya. Sejalan dengan pendapat Mudjijono (1995) yang menyatakan bahwa indikator sikap yang mencerminkan sikap sosial adalah saling menghargai, menahan diri, menerima perbedaan, saling membantu, peduli terhadap sesama, rela berkorban, kesadaran hukum, dan patuh pada aturan hukum.

Sikap jujur yang muncul dalam tema "Sejarah Peradaban Indonesia" ditunjukkan melalui mengerjakan sendiri tugas yang diberikan guru tanpa menjiplak tugas orang lain, mengerjakan soal penilaian tanpa mencontek, mengatakan dengan sesungguhnya apa yang terjadi/yang dialaminya dalam kehidupan sehari-hari, dan mengemukakan pendapat sesuia dengan apa yang diyakininya. Sikap disiplin ditunjukkan melalui perilaku mengikuti peraturan yang ada di sekolah, dan Tertib melaksanakan tugas. Sikap tanggung jawab ditunjukkan melalui perilaku menyelesaikan tugas yang diberikan, mengerjakan tugas atau pekerjaan rumah dan sekolah dengan baik, membuat laporan setelah selesai melakukan kegiatan. Sikap percaya diri ditunjukkan melalui perilaku berani tampil di depan kelas dan mencoba hal-hal baru yang bermanfaat.

Selanjutnya dari hasil wawancara terhadap budayawan, guru SBdP., guru kelas $\mathrm{V}$, dan orang tua siswa kelas $\mathrm{V}$ menunjukan adanya aspek-aspek budaya lokal yang dekat dengan aktivitas anak kelas tinggi dan perlu diimplementasikan dalam bentuk cerita anak. Ditemukan pula adanya kandungan nilai-nilai sosial yang dapat dituangkan ke dalamnya. Selain itu terdapat aktivitas budaya lokal lainnya yang dapat memunculkan nilai sikap sosial berdasarkan keterangan narasumber yakni permainan tradisional, bernyanyi, dan mengucapkan salam. Sikap jujur dapat dimunculkan pada aktivitas mendengarkan cerita (satua) dan permainan tradisional. Berdasarkan hasil wawancara terhadap para narasumber, terdapat beberapa satua yang dapat menanamkan perilaku jujur diantaranya siap selem, cupak gerantang, I Belog, Men tiwas lan men sugih, I Bawang teken I Kesuna, Tuwung Kuning, Pan Balang Tamak, I Siap Selem, Pedanda Baka, dan Kebo iwa. Dalam permainan tradisional yang dirasa mampu menanamkan nilai-nilai jujur adalah permainan Tembing (dengkleng), mecingklak, dan gangsing.. Berlanjut pada permainan tradisonal yang mampu menamkan nilai-nilai disiplin adalah Makering-keringan (kering keb), Megala-galaan, Main Tali, Tembing (dengkleng), meong-meongan, tajog, gangsing, dan magoak-goakan. Nilai-nilai disiplin juga dapat ditanamkan melalui cerita (satua) yaitu cupak gerantang, men tiwas lan men sugih, i bawang teken i kesuna, Tuwung Kuning, dan Kebo iwa.

Sementara untuk perilaku bertanggungjawab, dapat dituangkan ke dalam aktivitas permainan tradisional. Berdasarkan tabulasi hasil keterangan wawancara dari narasumber, permainan tradisional yang dapat mengembangkan perilaku bertanggungj jawab diantaranya megala-galaan, gowak-gowakan, dan meongmeongan. Sedangkan untuk perwujudan sikap 
sosial dalam perilaku percaya diri, dapat dimunculkan pada aktivitas bernyanyi (gending). Beberapa jenis gending yang sesuai menurut keterangan dari narasumber antara lain, ketut garing, bebek putih jambul, meong-meong, guak maling taluh, made cenik, sumping waluh, ratu anom, pupuh pucung, pupuh mijil. juru pencar, jenggot uban, pupuh maskumambang, dan pupuh ginada.

Hasil wawancara ini memunculkan pemahaman bahwa keterkaitan antara nilai sikap spiritual dan unsur budaya lokal bali cukup erta dengan aktivitas anak SD kelas tinggi. Maka dari itu, selain mendengarkan satua, aktivitas bermain permainan tradisional, bernyanyi (gending), dan mengucapkan salam perlu dimasukkan ke dalam buku cerita anak berbasis budaya lokal bali yang diharapkan mampu menjadi suplemen konten literasi mendampingi buku pelajaran kurikulum 2013

Berdasarkan hasil penelitian dan pembasahan di atas, dapat dirancang sebuah keterkaitan nilai-nilai sikap spiritual dan sikap sosial dengan budaya lokal untuk pembelajaran kelas $\mathrm{V}$ tema Sejarah Peradaban Indonesia. Adapun temuan tersebut diuraikan sebagai berikut: 1) nilainilai sikap spiritual yaitu ketaatan beribadah dan berperilaku syukur, 2) nilai-nilai sikap sosial yaitu jujur, disiplin, tanggung jawab, dan percaya diri, dan 3) Muatan budaya lokal yang meliputi berbagai jenis permainan

\begin{tabular}{|c|c|c|c|}
\hline No & Aspek & Temuan & $\begin{array}{c}\text { Budaya Lokal Yang } \\
\text { Mendukung }\end{array}$ \\
\hline \multirow[t]{3}{*}{1} & \multirow{3}{*}{$\begin{array}{l}\text { Nilai-nilai } \\
\text { Sikap } \\
\text { Spiritual }\end{array}$} & Ketaatan & Mendengarkan satua; \\
\hline & & Beribadah & $\begin{array}{l}\text { Maya denawa, cupak } \\
\text { gerantang, Men tiwas } \\
\text { lan men sugih, I Bawang } \\
\text { teken I Kesuna, Tuwung } \\
\text { Kuning, Pan Balang } \\
\text { Tamak, Pedanda Baka, } \\
\text { dan Kebo iwa. }\end{array}$ \\
\hline & & $\begin{array}{l}\text { Berperilaku } \\
\text { Syukur }\end{array}$ & $\begin{array}{l}\text { Sembahyang } \\
\text { (mebanten): mebanten } \\
\text { ajengan, } \quad \text { mebanten } \\
\text { ketipat. } \\
\text { mebanten } \\
\text { mebanten wedang, dan }, \\
\text { mebanten rahinan }\end{array}$ \\
\hline
\end{tabular}

\begin{tabular}{|c|c|c|c|c|}
\hline 2 & $\begin{array}{l}\text { Nilai-nilai } \\
\text { Sikap } \\
\text { Sosial }\end{array}$ & Jujur & a. & $\begin{array}{l}\text { Permainan } \\
\text { tradisional Tembing } \\
\text { (dengkleng), } \\
\text { mecingklak, dan }\end{array}$ \\
\hline
\end{tabular}

tradisional meliputi Makering-keringan (kering keb), Megala-galaan, Mecingklak, Main Tali, Tembing (dengkleng), meongmeongan, tajog, gangsing, dan magoakgoakan. Mendengarkan cerita meliputi cerita Maya denawa, mengkuwuk, Kunang-kunang ngaba api, cupak gerantang, I belog, men tiwas lan men sugih, I bawang teken I kesuna, Tuwung Kuning, Pan Balang Tamak, I Siap Selem, I Kekua. lutung teken kambing, Pedanda Baka, dan Kebo iwa. Aktivitas bernyanyi/magending diantaranya ketut garing, bebek putih jambul, meong-meong, guak maling taluh, made cenik, sumping waluh, ratu anom, pupuh pucung, pupuh mijil. juru pencar, jenggot uban, pupuh maskumambang, dan pupuh ginada. Jenis Salam budaya lokal yaitu Om Swastiastu, Rahajeng semeng, Selamat Pagi, dan selamat siang. Aktivitas Beribadah (Mebanten) yaitu mebanten ajengan/banten ketipat. canang, mebanten saiban, mebanten wedang, masegeh dan mebanten rahinan (purnama, tilem, saraswati, dll)

Adapun keterkaitan antar nilai-nilai sikap spiritual dan sikap sosial dengan nilainilai budaya lokal pendukungnya, disajikan dalam tabel 1. Berikut

Tabel 1. Keterkaitan Nilai-nilai SIkap Spiritual dan Sosial Dengan Budaya Lokal

Untuk Tema Bangga Sebagai Bangsa Indonesia di Kelas V Sekolah Dasar

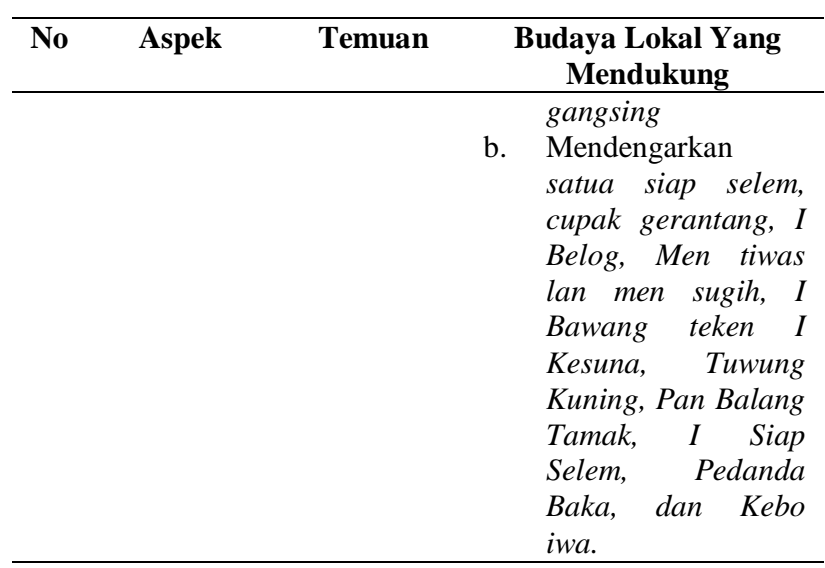




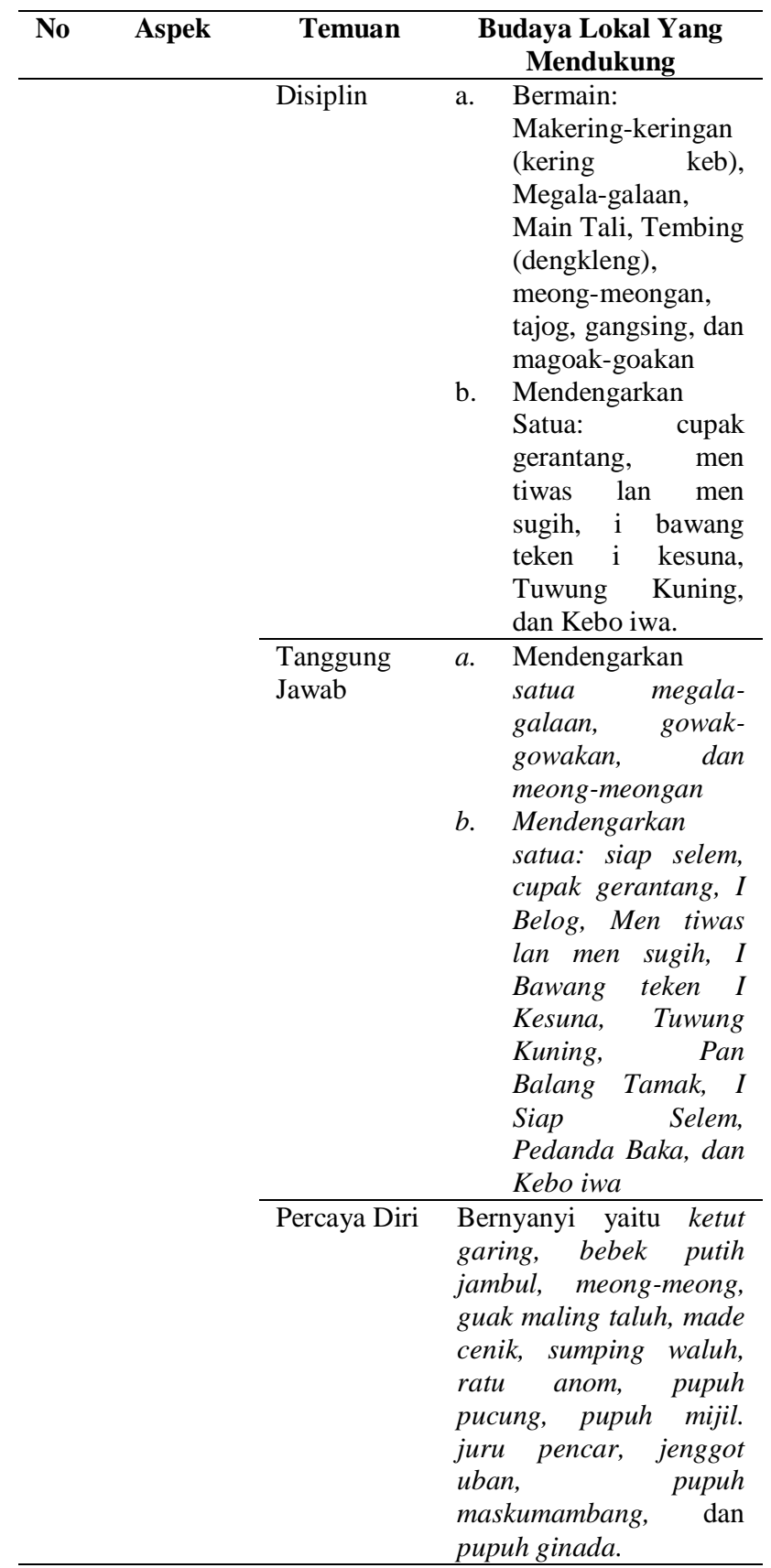

\section{SIMPULAN DAN SARAN}

Adapun yang dapat disimpulkan dari penelitian ini adalah sebagai berikut.

1. Nilai-nilai sikap spiritual yang termuat dalam pembelajaran kelas $\mathrm{V}$ pada tema Sejarah Peradaban Indonesia adalah ketaatan beribadah dan berperilaku syukur, dan nilai-nilai sikap sosial yang termuat adalah jujur, disiplin, tanggung jawab, dan percaya diri.Muatan pembelajaran yang termuat dalam pembelajaran kelas $\mathrm{V}$ pada tema Sejarah Peradaban Indonesia antara lain; Bahasa Indonesia (Teks Narasi, teks deskriptif, teks laporan sederhana), PKn (nilai persatuan dan kesatuan), Matematika (geometri), IPA (wujud dan bentuk benda), IPS (Kehidupan manusia dan kelembagaan sosial, ekonomi, pendidikan, dan budaya masyarakat), SBdP (Apresiasi warisan budaya), dan PJOK (Aktivitas fisik dan komponen kebugaran terkait kesehatan: kekuatan, daya tahan, kelenturan, dan komposisi tubuh, dan terkait keterampilan: kecepatan, ketepatan, kelincahan, keseimbangan, dan koordinasi). Aktivitas budaya lokal yang harus termuat dalam buku cerita anak yang dapat digunakan untuk menanamkan nilai-nilai sikap dan membelajarkan muatan pembelajaran adalah 1) permainan tradisional: Makeringkeringan (kering keb), Megala-galaan, Mecingklak, Main Tali, Tembing (dengkleng), meong-meongan, tajog, gangsing, dan magoak-goakan. 2) cerita meliputi cerita Maya denawa, mengkuwuk, Kunang-kunang ngaba api, cupak gerantang, I belog, men tiwas lan men sugih, I bawang teken I kesuna, Tuwung Kuning, Pan Balang Tamak, I Siap Selem, I Kekua. lutung teken kambing, Pedanda Baka, dan Kebo iwa. 3) bernyanyi/magending diantaranya ketut garing, bebek putih jambul, meong-meong, guak maling taluh, made cenik, sumping waluh, ratu anom, pupuh pucung, pupuh mijil. juru pencar, jenggot uban, pupuh maskumambang, dan pupuh ginada. 4) Salam budaya lokal yaitu Om Swastiastu, Rahajeng semeng, Selamat Pagi, dan selamat siang. 5) Beribadah (Mebanten) yaitu mebanten ajengan/banten ketipat. canang, mebanten saiban, mebanten wedang, masegeh dan mebanten rahinan (purnama, tilem, saraswati, dll).

Berdasarkan hasil penelitian dan pembahasan, dapat disusun sebuah prototipe teoretik buku cerita anak berbasis budaya lokal pada tema Sejarah Peradaban Indonesia kelas $\mathrm{V}$ sekolah dasar.

Berdasarkan simpulan penelitian yang telah dipaparkan, maka dapat diajukan beberapa saran sebagai berikut. 
Bagi pendidik, disarankan mampu mengembangkan teori pendidikan khususnya tentang peningkatan kualitas pembelajaran sikap dan muatan pembelajaran siswa kelas $\mathrm{V}$ sekolah dasar dengan menggunakan cerita anak bermuatan lokal tema Sejarah Peradaban Indonesia.

Bagi siswa, disarankan agar lebih meningkatkan perhatian minat dalam mendengarkan cerita anak guna menumbuhkan motivasi belajar yang akan membantu siswa dalam pengembangan sikap maupun muatan pembelajaran di sekolah dasar.

Agar tujuan penelitian ini tercapai optimal, maka hasil dari penelitian ini hendaknya dapat difungsikan sebagai landasan teoretik dalam merancang buku cerita anak berbasis budaya local untuk anak kelas tinggi yang nantinya dapat dijadikan sebagai suplemen pembelajaran mendampingi buku-buku pelajaran yang ada.

\section{DAFTAR PUSTAKA}

Dantes, N. 2014. Landasan Pendidikan Tinjauan dari Dimensi

Makropedagogis. Singaraja: Universitas Pendidikan Ganesha.

Departemen Pendidikan Nasional Republik Indonesia. 2003. Undang-undang Nomor 20 Tahun 2003 Tentang Sistem Pendidikan Nasional.

Departemen Pendidikan Nasional Republik Indonesia. 2006. Permendiknas No. 22 Tahun 2006 Tentang Standar Isi.

Farid, M. M. 2012. The effect of a story based programme on developing moral values at the kindergarten stage. Interdisciplinary Journal Of Contemporary Research In Business. Tersedia pada ijcrb.webs.com. Diakses pada tanggal 24 Desember 2016.

Ibrahim, R. 2001. Pembinaan perilaku sosial melalui pendidikan jasmani. Jakarta: Direktorat Jenderal Olahraga.

Kementerian Pendidikan dan Kebudayaan. 2016. Permendikbud Nomor 21 Tahun
2016 Tentang Standar Isi Pendidikan Dasar dan Menengah.

Lasmawan, Wayan. 2010. Menelisik Pendidikan IPS Dalam Perspektif Kontekstual-Empiris. Singaraja: Mediakom Indonesia Press Bali.

Manajemen Pendidikan Dasar dan Menengah Kementerian Pendidikan Nasional.

Marhaeni, A. A. I. N. 2013. Landasan dan Inovasi Pembelajaran. Singaraja: Universitas Pendidikan Ganesha.

Mayasari, dkk. 2014. "Pengaruh Model Pembelajaran Berbasis Masalah Terhadap Hasil Belajar Matematika Ditinjau Dari Gaya Kognitif Siswa Kelas V Sd Di Gugus II Kecamatan Mengwi”. E-Journal Program Pascasarjana Universitas Pendidikan Ganesha: Program Studi Pendidikan Dasar. Vol. 4 tahun 2014.

Mutiah, D. 2010. Psikologi Bermain Anak Usia Dini. Jakarta: Kencana Prenada Media Group.

Pemerintan Republik Indonesia. 2005. Peraturan Pemerintah Republik Indonesia Nomor 19 Tahun 2005.

Sudana, D. N. \& I Gede Astawan. 2013. Pendidikan IPA SD. Singaraja: Universitas Pendidikan Ganesha.

Sugiyono. 2014. Metode Penelitian Kuantitatif Kualitatif dan $R \& D$. Bandung: Alfabeta.

Sukesari, A. 2016. "Pengembangan Prototipe Buku Cerita Anak Bermuatan Budaya Lokal Melalui Analisis Muatan Sikap Dan Literasi Dini Pada Pembelajaran Tema Peristiwa Alam Kurikulum 2013 Kelas I Sekolah Dasar". Program Pascasarjana Universitas Pendidikan Ganesha.

Susanto, A. 2012. Teori Belajar \& Pembelajaran di Sekolah Dasar. Jakarta: Kencana Prenada Media Group.

Tarigan, H. G. 1995. Dasc ii ar Psikosastra. Bandung: Angkasa. 